\title{
RESÍDUOS URBANOS E SAÚDE AMBIENTAL: UMA ABORDAGEM HISTÓRICA NO MUNICÍPIO DE PRESIDENTE PRUDENTE-SP
}

\author{
Edilene Mayumi Murashita Takenaka
}

Faculdade de Tecnologia de São Paulo - FATEC, Presidente Prudente, SP. E-mail: edilene.takenaka@fatec.sp.gov.br

\section{RESUMO}

O processo de urbanização crescente trouxe uma nova realidade envolvendo a geração e a adequada disposição de resíduos sólidos. Tal aspecto é muito comum a vários municípios brasileiros e Presidente Prudente-SP encontra-se em meio a essa questão. O presente trabalho tem como objetivo mostrar a maneira encontrada pela administração pública municipal para gerenciar a disposição desses resíduos no período entre 1923 a 2020. Para tanto, a metodologia utilizada foi o levantamento de dados a partir da documentação direta e indireta, bem como a adoção da técnica da observação direta intensiva e entrevistas realizadas junto a órgãos públicos municipais. Conclui-se que a administração pública municipal tem um longo caminho a percorrer e ações a realizar para chegar a uma forma de gerenciamento que propicie um mínimo de danos à saúde ambiental do município.

Palavras-chave: Resíduos sólidos. Meio ambiente. Gerenciamento. Saúde. Urbanização.

\section{URBAN WASTE AND ENVIRONMENTAL HEALTH: A HISTORICAL APPROACH IN THE CITY PRESIDENTE PRUDENTE-SP}

\begin{abstract}
The growing urbanization process brought a new involving the creation of solid waste. This aspect ia very common in several Brazilian municipalities and Presidente Prudente - SP is in the midst of the issue. The present work aims to show the way found by the municipal public administracion to manage the disposal of those wastes on period between 1923 and 2020. The methodology used was data collection from direct and indirect documentation, as well as adoption of direct observation techniques and interviews conducted with local government agencies. We consider that the municipal public management has a long way to travel and actions to do in order to find a way of management which triggers minimal damages to the city environmental health.
\end{abstract}

Keywords: Solid waste. Environmental. Management. Health. Urbanization.

\section{INTRODUÇÃO}

O deslocamento da população rural para áreas urbanizadas associa-se, historicamente, ao desenvolvimento da civilização e da tecnologia. A população promove esse fenômeno, também conhecido como êxodo rural, em busca de melhores condições de vida (maior oferta de empregos, estudo para os filhos e atendimento médico entre outros).
De acordo com Arana e Takenaka (2016), a urbanização estrondosa na maior parte dos países desenvolvidos industrializados veio a ocorrer a partir da segunda metade do século XIX como resultado da Revolução Industrial. Tal fenômeno, caracterizado pelo deslocamento de moradores do campo para a cidade culmina com a redistribuição da população rural em espaços urbanos em busca de mais e melhores oportunidades. 
O progresso tecnológico e a industrialização crescente consolidaram a atividade industrial como essencialmente urbana, ocasionando uma grande migração dos trabalhadores rurais que, expulsos pela mecanização no campo, optaram por partir para as cidades, atraídos pela possibilidade de melhores condições de vida. (ARANA; TAKENAKA, 2016).

No Brasil, o processo de saída do campo para a cidade seguiu o mesmo roteiro com algumas décadas de diferença tendo início em meados do século XX. Movimento manifesto pelo aumento da população e o desenvolvimento do espaço urbano em que, moradores das áreas rurais passaram a buscar as cidades objetivando encontrar mais e melhores opções de trabalho e acesso à saúde e educação, surgindo assim, uma correlação imediata entre emprego e o inchaço nos centros urbanos. (SANTOS, 1998)

Ainda, segundo Santos (1998), pode-se afirmar que, no Brasil, ocorreu um dos mais rápidos processos de urbanização do mundo: em 1940 as cidades abrigavam $46 \%$ da população do país, em 1975 esse índice já era de 61\%, em 1991 apresentava-se em $75 \%$ e a previsão da ONU (Organização das Nações Unidas) é de que em 2025 esse índice atinja a marca de 88\%.

A concentração populacional em áreas urbanas trouxe alguns desequilíbrios à medida em que houve a ampliação da demanda por moradias, alimentação, escolas, hospitais, saneamento básico entre outros, exigindo um planejamento urbano que nem sempre presente nos centros urbanos.

De acordo com Deák e Schiffer (1999) e Ojima (2007), quando nos referimos ao processo de crescimento urbano, dois fatores devem ser considerados: o populacional e o padrão de expansão física das ocupações urbanas.

O primeiro representa um desafio em si mesmo quando exerce um importante peso na expansão da infraestrutura urbana. O segundo deve ser entendido como essencial para que esse crescimento possa se dar com maior ou menor custo social, refletindo impactos sobre as formas de reprodução social e a sustentabilidade ambiental.

O aumento populacional e sua concentração nos centros urbanos apresenta, ainda, uma questão essencial: o que fazer com os resíduos sólidos gerados nos domicílios, ao considerarmos que, de acordo com o Instituto Brasileiro de Geografia e Estatística - IBGE (2007) cada brasileiro gera em torno de 700 gramas de resíduos por dia.

Segundo Takenaka (2008, p.02):

A crescente concentração
da população brasileira,
nos centros urbanos, traz
a necessidade de atender
a novas demandas por
bens de consumo sejam
eles, duráveis ou não-
duráveis.
concentração, quando não
acompanhada de um
planejamento adequado,
contribui para o
agravamento de uma das
principais características
das atividades humanas: a
geração de resíduos.

Reforçando essa constatação, temos as contribuições de Oliveira (2002), Eigenheer (1999) e Magera (2003) que são unânimes ao afirmar que qualquer atividade humana tem por resultado a geração de resíduos, seja ao se alimentarem, ao construírem seus lares, ao se distraírem com atividades de lazer ou, principalmente, ao produzirem mercadorias e serviços.

A geração de resíduos está sempre presente e mesmo após o término da vida útil dos produtos ou bens consumidos, temos ainda mais resíduos que são somados àqueles já dispostos nos lixões e aterros, perfazendo um montante com alto potencial poluidor.

Assim sendo, salientamos que a geração desenfreada de resíduos e sua inadequada disposição final constituem grandes focos de poluição ambiental, ocasionando ainda, problemas de ordem política, econômica e social.

o que fazer com esses resíduos gerados passa a fazer parte de um dos desafios das administrações públicas municipais, estaduais e federais.

O município de Presidente Prudente-SP encontra-se em meio a essa problemática. Segundo dados fornecidos pela Companhia Prudentina de Desenvolvimento (PRUDENCO), empresa de economia mista, responsável pelo serviço de limpeza pública municipal que atinge cerca de $98 \%$ da malha urbana, o total de resíduo sólido coletado diariamente, é de, aproximadamente, 200 toneladas. Considerando que a população prudentina é de cerca de 
227.000 habitantes ${ }^{1}$, calculamos que, em média, cada habitante gera cerca de 900 gramas de resíduos sólidos, diariamente.

O material coletado diariamente pela PRUDENCO, é disposto em uma área próxima da malha urbana, denominada lixão ${ }^{2}$, desde 0 ano de 1997 e que se apresenta sem nenhum tipo de preparo de solo, drenagem ou impermeabilização, sendo compactado e coberto por camadas de terra, todos os dias.

O presente trabalho tem como objetivo mostrar em uma abordagem histórica, a maneira encontrada pela administração pública municipal de Presidente Prudente-SP para gerenciar a disposição desses resíduos no período entre 1923 a 2020.

\section{METODOLOGIA}

Para o desenvolvimento do presente trabalho foi utilizado, inicialmente, o levantamento de dados a partir da documentação indireta em fontes primárias e secundárias. As fontes primárias foram obtidas a partir de análises em documentos cedidos secretaria de desenvolvimento do município. As fontes secundárias envolveram a busca de informações a partir de análises e discussões publicadas sobre $o$ assunto.

As fontes secundárias utilizadas passaram por um levantamento da vasta literatura existente relacionada ao tema pesquisado, seguido de revisão bibliográfica, o que permitiu o contato direto com questões existentes e explorar novos conhecimentos sobre o assunto tratado.

Utilizou-se também, a documentação direta através de pesquisa de campo e, finalmente, a técnica da observação direta intensiva.

\section{RESULTADOS}

O município de Presidente Prudente está localizado na região oeste do Estado de São Paulo. Teve suas origens com o surgimento da chamada Vila Goulart no dia 14 de setembro de 1917, elevada a município pela Lei Estadual no1.798/21 de 28 de novembro de 1921, e sendo

\footnotetext{
1 População estimada. Disponível em <http://www.ibge.gov.br/cidadesat/painel/painel.php?codmun=354 140> Acesso em 16/06/2020.

${ }^{2}$ Em relatório enviado ao Ministério das Cidades (2004), a Prefeitura Municipal de Presidente Prudente classifica o atual lixão como "aterro controlado". Contudo, nas reuniões e atividades informais, a população e os próprios representantes da administração municipal referem-se ao local como lixão.
}

instalado em 27 de agosto de 1923. (TAKENAKA, 2008).

Como a maioria das cidades brasileiras, Presidente Prudente tem apresentado condições inadequadas em relação ao problema da geração e disposição de resíduos sólidos desde sua fundação.

\section{ABORDAGEM HISTÓRICA E SITUAÇÃO ATUAL DO GERENCIAMENTO DE RESÍDUOS SÓLIDOS URBANOS EM PRESIDENTE PRUDENTE-SP}

Segundo Mazzini (1997) e Takenaka (2008), a administração pública municipal de Presidente Prudente-SP, em comum com o histórico de vários municípios brasileiros, adotou durante décadas as seguintes práticas, em relação aos resíduos sólidos urbanos: o material orgânico coletado era destinado para alimentação animal e o restante era utilizado para aterrar valas e voçorocas em áreas públicas.

A escolha e utilização dos locais para a disposição do lixo obedeciam a alguns critérios específicos como o terreno ser acidentado, com áreas erodidas, voçorocas ou ravinas e próximas da malha urbana.

Segundo Mazzini (1997) e Takenaka (2008), a maioria das áreas destinadas ao aterro (lixão), pertenciam ao poder público e, devido ao relevo acidentado, não eram incorporadas à malha urbana, sendo lentamente ocupadas por pessoas de baixa renda, com o aparecimento de moradias em condições de extrema precariedade.

Os locais utilizados, pela administração pública municipal no período de 1923 a 2020, para a disposição final dos resíduos sólidos urbanos coletados em Presidente Prudente, podem ser observados na figura 1. 
Figura 1. Localização das áreas de disposição final de resíduos sólidos urbanos no município de Presidente Prudente-SP (1923-2008)

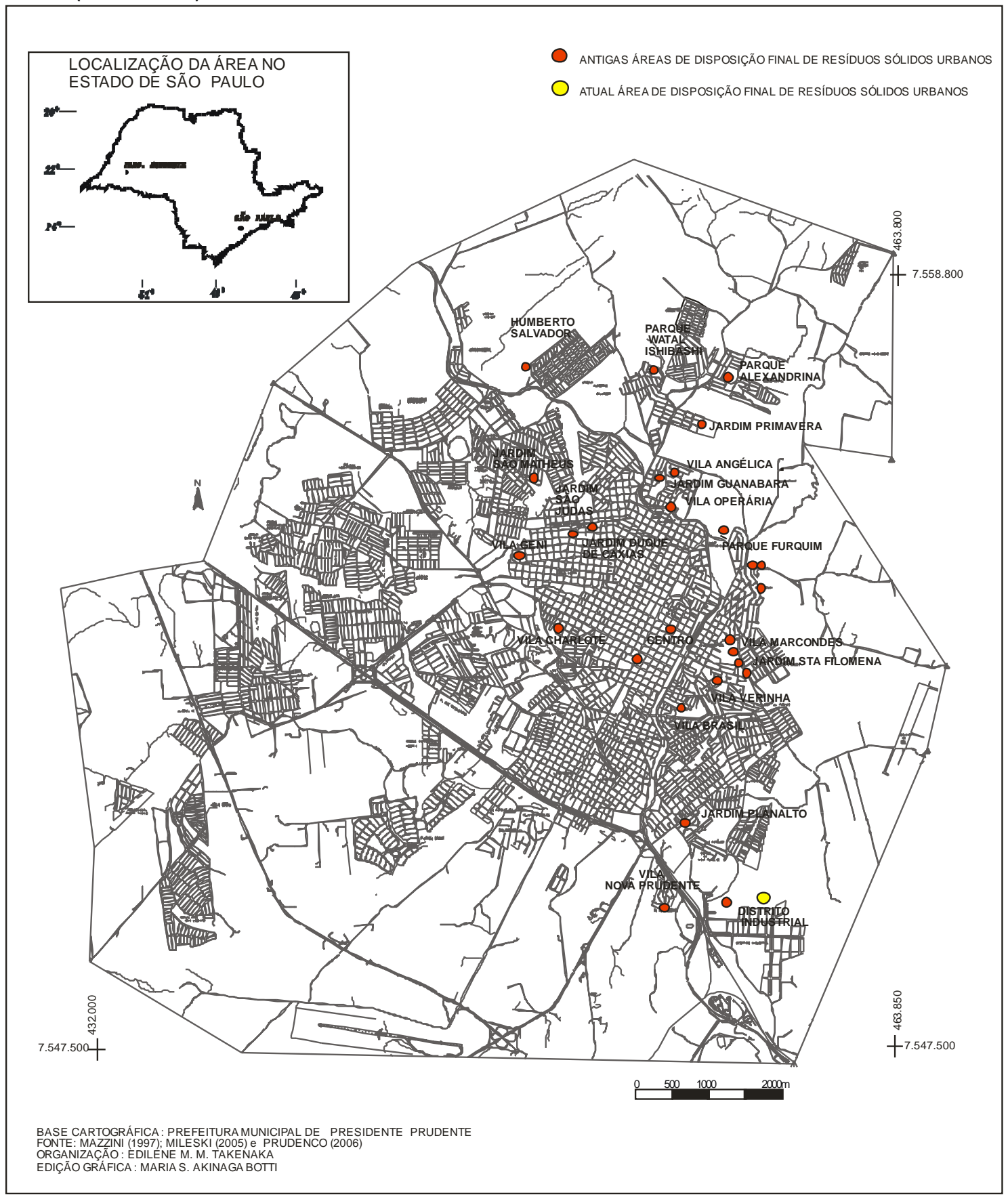

\section{PRESIDENTE PRUDENTE-SP \\ ÀREAS DE DISPOSIÇÃO FINAL DE RESÍDUOS SÓLIDOS}

Fonte: TAKENAKA $(2008$, p.68)

* a área no Distrito Industrial continua a ser utilizada para fins de deposição de resíduos sólidos até a presente data (junho-2020).

Em alguns casos, como os citados no trabalho de Amorim (1993), Mazzini (1997), Mileski (2006) e Takenaka (2008), a própria população vizinha a essas áreas acidentadas de fundo de vale, ravinas e voçorocas aceitavam a prática de sua utilização como "lixões" acreditando que, após sua desativação, os locais receberiam a cobertura de terra e seriam reintegrados ao meio urbano através de trabalhos de paisagismo, com a instalação de áreas de lazer como praças, campo de futebol, entre outros. 
Para uma visão, em ordem cronológica, dos locais utilizados para a disposição final dos resíduos sólidos urbanos no município de
Presidente Prudente-SP no período de 1923 a 2020 atentamos para a tabela 1.

Tabela 1. Locais utilizados para a disposição final dos resíduos sólidos urbanos, no município de Presidente Prudente-SP (1923-2020)

\begin{tabular}{|c|c|}
\hline PERÍODO & ÁREAS UTILIZADAS \\
\hline 1923 & - Centro \\
\hline 1940 & - Centro \\
\hline 1955 & - Vila Charlote \\
\hline 1969 & - Vila Charlote \\
\hline $1970-1972$ & - Jardim Primavera* \\
\hline 1973 & - Vila Verinha \\
\hline $1974-1990$ & - Jardim Santa Filomena* \\
\hline $1975-1980$ & - Jardim São Judas* \\
\hline 1976 & - Vila Geni \\
\hline 1978 & - Parque Alexandrina (primeira área) \\
\hline 1979 & - Jardim Duque de Caxias \\
\hline 1981 & - Parque Furquim (primeira área) \\
\hline $1982-1989$ & - Vila Marcondes* \\
\hline 1982 & - Parque São Mateus \\
\hline 1983 & - Vila Nova Prudente \\
\hline 1985 & - Parque Furquim (segunda área) \\
\hline 1986 & - Curtume Crepaldi \\
\hline 1987 & - Parque Alexandrina (segunda área) \\
\hline 1987 & - Parque Furquim (terceira área) \\
\hline 1988 & - Parque Watal Ishibashi \\
\hline 1988 & - Humberto Salvador \\
\hline 1990 & - Jardim Planalto \\
\hline 1990 & - Vila Brasil \\
\hline 1991 & - Parque Furquim (quarta área) \\
\hline 1994 & - Vila Operária \\
\hline 1996 & - Jardim Guanabara \\
\hline 1997 & - Vila Angélica \\
\hline $1997-2020$ & - Distrito Industrial ** \\
\hline
\end{tabular}

Fonte: TAKENAKA $(2008, \mathrm{p} .69)$

* áreas utilizadas por várias vezes em diferentes períodos.

** a área no Distrito Industrial continua a ser utilizada para fins de disposição de resíduos sólidos até a presente data (junho/2020).

O predomínio da responsabilidade da administração municipal, acerca da ação direta na coleta e disposição de resíduos sólidos urbanos, sempre foi uma característica de Presidente Prudente.

No início de 1993, a PRUDENCO passou a ser responsável, através de contrato firmado com a Prefeitura Municipal, pela coleta e transporte dos resíduos sólidos até a sua disposição final, permanecendo responsável até os dias atuais ${ }^{3}$. 0

${ }^{3}$ Ofício no 082/2007/SÃO/SECAD de 09/04/07 (Processo no 5.301/2007) trabalho de coleta e disposição realizado pela PRUDENCO manteve as características anteriores, apenas a realização da coleta e disposição passou a ser da empresa contratada.

Desde sua contratação, a PRUDENCO atua na coleta e disposição dos resíduos sólidos urbanos com frota própria de caminhões e motoristas e trabalhadores coletores contratados por concurso público. Os moradores dos bairros atendidos pelo serviço de "coleta de lixo" recebem a atenção dos caminhões coletores com periodicidade que variam de duas ou três vezes 
por semana e diariamente, dependendo de estimativas da quantidade de resíduos gerados no local. Ainda, sob sua responsabilidade, está a contratação de garis e margaridas, nome dado a homens e mulheres contratados também por concurso público, e que atuam na limpeza do município com a varrição de ruas e calçadas. (TAKENAKA, 2008)

Após a realização da coleta dos resíduos sólidos urbanos, os caminhões se dirigem ao Distrito Industrial e depositam o total coletado na área destinada pela administração pública municipal.

Atualmente, a área utilizada para a disposição dos resíduos sólidos urbanos coletados pela PRUDENCO encontra-se cercada e, após a disposição dos resíduos, uma camada de terra é espalhada e compactada sobre o local.

\section{EFEITOS AMBIENTAIS DA INADEQUADA DISPOSIÇÃO DOS RESÍDUOS SÓLIDOS URBANOS}

O presente trabalho trata de um estudo sobre o gerenciamento de resíduos sólidos urbanos que, segundo Teixeira (2001), representa a associação de diferentes tipos de resíduos sólidos que ficam sob a responsabilidade da administração pública municipal, englobando um conjunto de resíduos gerados nas cidades e que tenham um manuseio compatível entre si.

Atenção para o fato de que, neste estudo, consideramos as normas da ABNT em que os resíduos sólidos gerados na indústria, na construção civil e nos serviços de saúde ${ }^{4}$, ainda que gerados em instalações localizadas na área urbana, demandam procedimentos específicos e permitem que seus geradores sejam, facilmente, identificados e responsabilizados pelo seu manuseio e destinação final.

Entretanto, independentemente de assumirem a responsabilidade pela totalidade dos resíduos sólidos urbanos gerados, a administração pública municipal deve estabelecer normas e procedimentos para seu manuseio e destinação, a fim de minimizar os impactos causados por todos uma vez em que, se tratando de resíduos sólidos, a sua condição de degradabilidade pode trazer impactos nocivos ao meio ambiente, caso não sejam, devidamente, gerenciados.

\footnotetext{
4 Em alguns municípios brasileiros, a prefeitura municipal, através de contratos de prestação de serviços junto a empresas particulares ou de economia mista, acaba por responsabilizar-se pela coleta e destino final dos resíduos dos serviços de saúde, da indústria e da construção civil.
}

Segundo Lima (2001, p.32-33), os resíduos sólidos urbanos são constituídos de substâncias:

- Facilmente degradáveis: restos de comida, sobras de cozinha, folhas, capim, cascas de frutas, animais mortos e excrementos;

- Moderadamente degradáveis: papel, papelão e outros produtos celulósicos;

- Dificilmente degradáveis: trapo, couro, pano, madeira, borracha, cabelo, pena de galinha, ossos e plásticos;

- Não degradáveis: metal nãoferroso, vidro, pedras, cinzas, terra, areia e cerâmicas.

Tais características explicam o fato de que os resíduos sólidos urbanos dispostos diretamente sobre o solo, em lixões a céu aberto ou em aterros controlados sem a devida instalação de sistemas de proteção e obras de contenção como determina a legislação pertinente à matéria, passam a constituir um grave problema sanitário.

Segundo D'Almeida e Vilhena (2000) e Eigenheer (1999), a disposição dos resíduos sólidos urbanos em locais inadequados traz grande desconforto e inúmeros malefícios à saúde dos moradores da região, como por exemplo: o mau cheiro e a proliferação de moscas, roedores, baratas e outros vetores que atuam como transmissores de enfermidades causadas pelo contato com agentes contaminados.

Alguns tipos de resíduos sólidos urbanos como plásticos, latas e vidros persistem por muitos anos no meio ambiente e outros como os materiais orgânicos decompõem-se mais rapidamente originando o chorume, líquido escuro e malcheiroso produzido a partir da ação enzimática dos micro-organismos que penetra pela terra levando substâncias contaminantes para o solo e para o lençol freático.

Segundo Takenaka (2008), os resíduos sólidos urbanos gerados no município de Presidente Prudente-SP até meados do século XX eram constituídos de matéria orgânica $e$ destinado à alimentação animal em chácaras e sítios localizados, na época, próximos à malha urbana e, os resíduos sólidos coletados no município e utilizados para aterrar valas e voçorocas em áreas públicas era constituído, em sua maior parte, de restos de construção civil. 
Tem-se como exemplo, uma área situada na Avenida Coronel José Soares Marcondes esquina com a Rua Bela, relativamente próxima ao centro da cidade à cerca de 700 metros da Catedral e da Praça principal.

Tal área, na década de 1940, era comumente conhecida como "Buracão do Bôscoli" e foi utilizado para a disposição dos resíduos sólidos coletados por mais de dez anos. Conforme figura 2, o local é, atualmente, conhecido como Parque de Uso Múltiplo (PUM) e cumpre sua função servindo à população como recinto para a prática de esportes e demais atividades de lazer.

Outro exemplo situa-se na Vila Charlote que, em 1969, foi utilizado para a disposição final dos resíduos sólidos coletados. Hoje, o local representado pela figura 3 é conhecido como Parque do Povo, o local apresenta extensa área para a prática de esportes e recreação, sendo muito visitado nos períodos da manhã, da tarde, finais de semana e feriados por um público de todas as faixas etárias.

Figura 2. Antiga área utilizada para a disposição final de resíduos sólidos urbano transformada em Parque de Uso Múltiplo

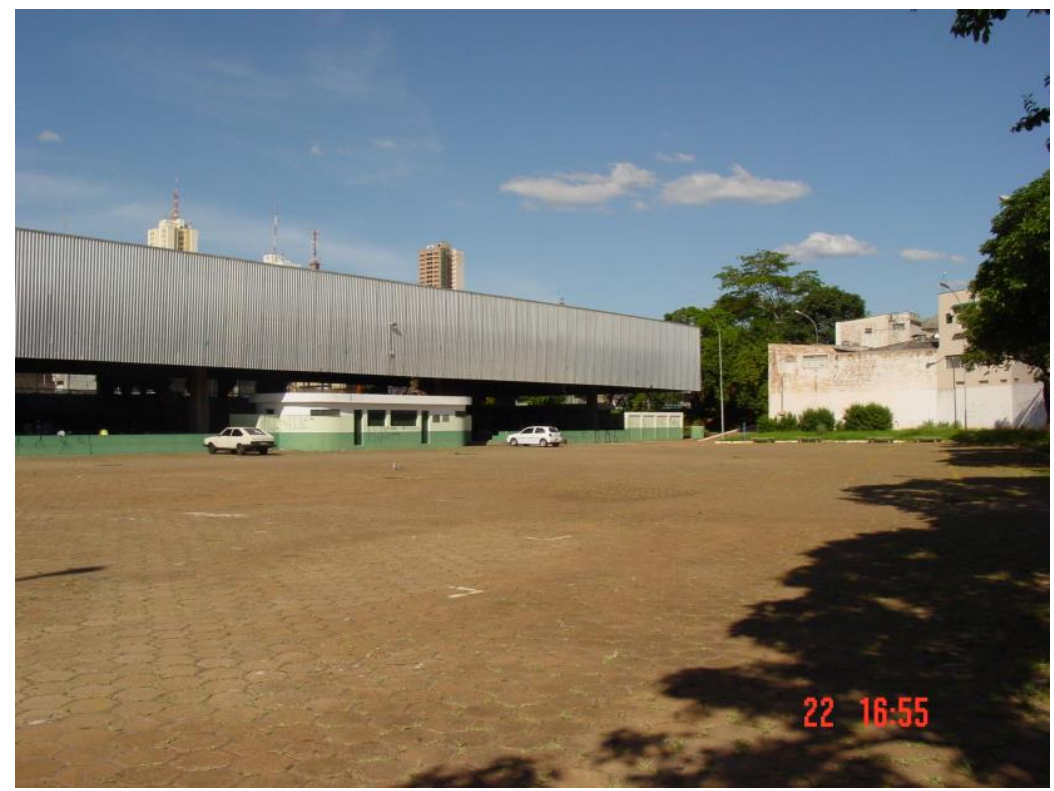

Fonte: TAKENAKA (2008, p.72)

Figura 3. Vila Charlote: Antiga área utilizada para disposição final de resíduos sólidos urbanos

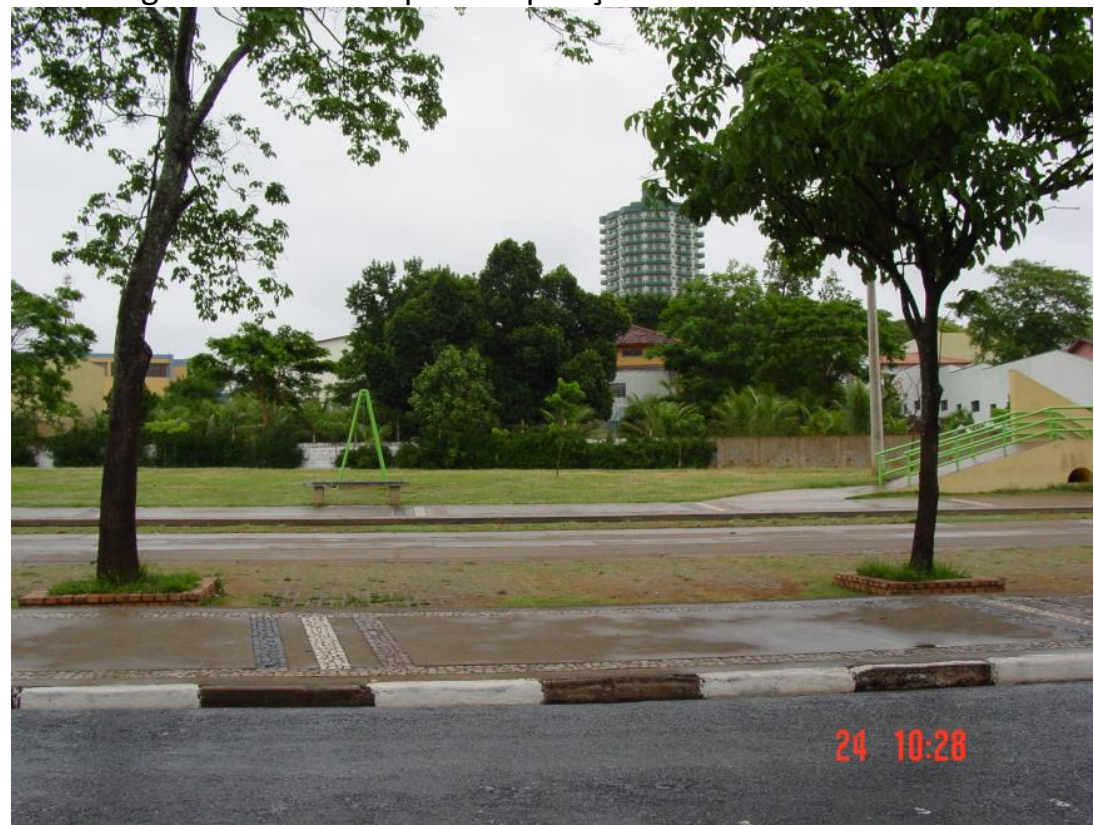

Fonte: TAKENAKA (2008, p.74) 
Santos (1996, p. 164), afirma que: "as novas atividades exigem um lugar no espaço e impõem uma nova arrumação para as coisas, uma disposição diferente para os objetos geográficos, uma organização do espaço diferente daquela que antes existia".

\section{DISCUSSÃO}

A partir de 1997, o Ministério Público do Estado de São Paulo, através da Promotoria de Justiça do Meio Ambiente de Presidente Prudente e da Secretaria Estadual do Meio Ambiente cobram um termo de compromisso de ajustamento (TCA), firmado pela Prefeitura Municipal, de encerrar a disposição de resíduos sólidos no lixão, localizado próximo ao Distrito Industrial e providenciar novo local, seguindo as normas de licenciamento ambiental.

Dessa forma, a partir de 1997, a administração pública municipal viu-se forçada a adotar uma postura mais adequada em relação à disposição final dos resíduos sólidos urbanos coletados.

De acordo com os estudos de Takenaka (2008), desde 17 de abril de 1997, a PRUDENCO utiliza para a disposição de resíduos sólidos uma grande área ${ }^{5}$, no Distrito Industrial, localizada a sudeste do perímetro urbano e bem próxima aos bairros da periferia.

A utilização do local dividiu-se, inicialmente, em duas áreas: a primeira, cuja disposição dos resíduos era realizada em uma encosta, lançados a partir do contorno elevado do vale, às margens do Córrego Gramado e que já esgotou sua vida útil e, a partir disso, passou-se a ser utilizada uma segunda área, anexa. Tal área pertence à mesma sub-bacia de contribuição do Córrego Gramado e a declividade do terreno favorece o deslocamento, via força gravitacional, do material produzido na decomposição dos resíduos depositados - o chorume - até alcançar um pequeno córrego do vale próximo, formando uma lagoa. (PREFEITURA MUNICIPAL DE PRESIDENTE PRUDENTE, 1999 ; LEAL, 2002).

Em relação ao chorume gerado, D'Almeida e Vilhena (2000), afirmam que a quantidade de água contida na massa do resíduo orgânico (seu teor de umidade) tende a solubilizar substâncias presentes nos mesmos dando origem a uma mistura líquida com

\footnotetext{
${ }^{5}$ Segundo dados da PRUDENCO, tal área possui aproximadamente dezessete mil metros quadrados.
}

composição química bastante variável provocada pela sua decomposição biológica pela ação de micro-organismos. Tal decomposição biológica dá-se em três fases:

- Aeróbica: apresenta liberação de calor e a elevação de temperatura pode ocasionar a formação de chorume com alta concentração de sais contendo metais como chumbo e mercúrio;

- Acetogênica: apresenta redução da concentração de carbono orgânico, altos níveis de amônia e largo espectro de metais, representando considerável potencial de risco para o meio ambiente. A fase anaeróbia pode demorar vários anos para estar completa;

- Metanogênica: etapa em que os compostos orgânicos simples formados na fase acetogênica a ser consumidos por bactérias estritamente anaeróbias, chamadas bactérias metanogênicas, dão origem ao metano e ao gás carbônico.

Assim, dadas as características da composição do chorume em suas fases distintas, sua infiltração no solo pode acarretar a contaminação de águas superficiais e subterrâneas e o assoreamento dos riachos, por apresentar uma alta concentração de matéria orgânica. Com a contaminação do lençol freático pode ocorrer a poluição de poços artesianos ou semiartesianos causando endemias e desenvolvendo surtos epidêmicos na população pois, como a composição físico-química do chorume varia muito em suas diferentes fases, o líquido negro pode conter altas concentrações de metais pesados e de micro-organismos nocivos à saúde humana.

O chorume pode permanecer por décadas no solo mesmo após o encerramento do lixão, exigindo ações corretivas durante vários anos com o objetivo de remediar a contaminação.

Atualmente, a prefeitura municipal providenciou a implantação de alguns drenos e valetas para o escoamento do material líquido resultado da decomposição da matéria orgânica depositada, entretanto, como não houve a impermeabilização da base do aterro com argila ou manta, os riscos de contaminação do solo continuam latentes.

\section{CONSIDERAÇÕES FINAIS}

Verificou-se que as áreas localizadas na parte central da cidade apresentam-se em boas condições e aquelas localizadas em bairros 
periféricos, apresentam-se na maior parte, como áreas de lazer com campos de futebol e praças.

Entretanto, a área atualmente utilizada para a disposição final de resíduos sólidos coletados no município, encontra-se inadequada uma vez que não obedece a critérios operacionais de modo a evitar danos ou riscos à saúde pública visando minimizar os impactos ambientais.

O ideal para o município é a viabilização de uma área que atenda aos critérios citados anteriormente e que possam caracterizar tal área como um aterro sanitário com licenciamento ambiental junto à CETESB.

\section{REFERÊNCIAS}

AMORIM, M. C. C. T. Análise ambiental e qualidade de vida em Presidente Prudente-SP. 1993. Dissertação (Mestrado em Geografia) Faculdade de Ciências e Tecnologia, Universidade Estadual Paulista, Presidente Prudente, 1993.

ARANA, A. R. A.; TAKENAKA, E. M. Economia solidária e meio ambiente: Ações sociais na coleta seletiva de Presidente Prudente - SP. Semioses, Rio de Janeiro, v. 10, p. 1-12, 2016. Doi:

https://doi.org/10.15202/1981996X.2016v10n2p 1

D'ALMEIDA, M. L. O.; VILHENA, A. (coord.) Lixo municipal: manual de gerenciamento integrado. 2. ed. São Paulo: IPT/CEMPRE, 2000.

DEÁK, C. ; SCHIFFER, S. R. (orgs.). O processo de Urbanização no Brasil. 1. ed., São Paulo: EDUSP, 1999.

EIGENHEER, E. M. Lixo e vanitas: considerações de um observador de resíduos. 1999. Tese (Doutorado em Educação) - Faculdade de Educação, Universidade Federal Fluminense, Niterói, 1999.

IBGE. Instituto Brasileiro de Geografia e Estatística. Pesquisa de informações básicas municipais: perfil dos municípios brasileiros. Gestão pública-2006. Rio de Janeiro, 2007.

LEAL, A. C. (coord.). Educação ambiental e o gerenciamento integrado de resíduos sólidos em Presidente Prudente-SP: desenvolvimento de metodologias para coleta seletiva, beneficiamento do lixo e organização do trabalho. Presidente Prudente: UNESP/FAPESP. Relatório Científico, Fase I, 2002.

LIMA, J. D. Gestão de resíduos sólidos urbanos no Brasil. Rio de Janeiro: ABES, 2001.

MAGERA, M. Os empresários do lixo: um paradoxo da modernidade. Campinas: Átomo, 2003.

MAZZINI, E. J. T. De lixo em lixo em Presidente Prudente (SP): novas áreas velhos problemas. 1997. Trabalho de Conclusão de Curso (Graduação em Geografia) - Faculdade de Ciências e Tecnologia, Universidade Estadual Paulista, Presidente Prudente, 1997.

MILESKI, M. M. Qualidade de vida nas proximidades das antigas e atuais áreas de disposição final de resíduos sólidos em Presidente Prudente-SP. 2006. 195 p. Trabalho de Conclusão de Curso (Graduação em Geografia) - Faculdade de Ciências e Tecnologia, Universidade Estadual Paulista, Presidente Prudente, 2006.

OJIMA, R. Dimensões da urbanização dispersa e proposta metodológica para estudos comparativos: uma abordagem socioespacial em aglomerações urbanas brasileiras. Revista Brasileira de Estudos de População, São Paulo, v. 24, n. 2, Dec. 2007. Doi: https://doi.org/10.1590/S0102$\underline{30982007000200007}$

OLIVEIRA, A. S. D. Método para viabilização da implantação de plano de gerenciamento integrado de resíduos sólidos: o caso do município do Rio Grande-RS. 2002. 230 p. Tese (Doutorado em Engenharia de Produção) Universidade Federal de Santa Catarina, Florianópolis, 2002.

PREFEITURA MUNICIPAL DE PRESIDENTE PRUDENTE. Relatório Ambiental Preliminar-RA. Set. 1999.

SANTOS, M. Por uma geografia nova. São Paulo: HUCITEC, 1996.

SANTOS, M. A urbanização brasileira. 1. ed., São Paulo: HUCITEC, 1998. 
TAKenAKA, E. M. M. Políticas Públicas de Gerenciamento Integrado de Resíduos

Sólidos Urbanos no Município de Presidente Prudente-SP. 2008, 232 f. Tese (Doutorado em Geografia) - Universidade Estadual Paulista, 2008.

TEIXEIRA, B. A. N. Gestão dos Resíduos sólidos: desafio para as cidades. In: CARVALHO, P. F. ; BRAGA, R. (org.) Perspectivas de gestão ambiental em cidades médias. Rio Claro: UNESPIGCE-Laboratório de Planejamento MunicipalDEPLAN, 2001. 